\title{
Avaliação do uso da glicerina proveniente da produção de biodiesel na conservação de peças anatômicas ${ }^{1}$
}

\author{
Yuri K. Carvalho ${ }^{2 *}$, Kelen C. Zavarize ${ }^{3}$, Luciana dos S. Medeiros ${ }^{2}$ e Pedro P. Bombonato ${ }^{4}$
}

\begin{abstract}
Carvalho Y.K., Zavarize K.C., Medeiros L.S. \& Bombonato P.P. 2013. [Evaluation of the glycerin from biodiesel production in the preservation of anatomical parts.] Avaliação do uso da glicerina proveniente da produção do biodiesel na conservação de peças anatômicas. Pesquisa Veterinária Brasileira 33(1):115-118. Centro de Ciências Biológicas e da Natureza, Universidade Federal do Acre, Rodov. BR $364 \mathrm{Km} \mathrm{4,} \mathrm{Rio} \mathrm{Branco,} \mathrm{AC}$ 69915-900, Brazil.E-mail: ykaracas@yahoo.com.br

Pure glycerin is widely used for conservation of anatomical parts, which is very efficient and not toxic to the handlers. Nevertheless pure glycerin is extremely expensive and unaffordable for many anatomy laboratories. The purpose of the study was to demonstrate the viability of semi-purified glycerin from biodiesel production for preservation of anatomical parts. Fifteen hearts and 30 kidneys from pigs were studied. The glycerin from a biodiesel plant had the following composition: $80.5 \%$ glycerol, $12.8 \%$ humidity, $6.3 \% \mathrm{NaCl}$ and $0.4 \%$ fatty acids. The organs were measured, analyzed and photographed before and after preservation protocol. The semi-purified glycerin caused no reduction in the dimensions of anatomical structures (mass, height and width) of statistical difference. Characteristics of consistency and flexibility of the anatomical parts was preserved. Additionally the costs and the production of toxic gases were reduced. The main achievement of this study was preservation of the morphological characteristics and improvement of the teaching and learning process.
\end{abstract}

INDEX TERMS: Semipurified glycerin, conservation, biodiesel, anatomical parts.

RESUMO.- 0 uso da glicerina pura é amplamente empregada na conservação de peças anatômicas, a qual é muito eficiente e não tóxica para os manipuladores, porém é extremamente cara e inviável para muitos laboratórios de anatomia. 0 propósito do estudo foi demonstrar a viabilidade da glicerina semipurificada proveniente da produção do biodiesel na conservação de peças anatômicas. 0 trabalho utilizou 15 corações e 30 rins de suínos provenientes de frigorífico. A glicerina foi adquirida em usina de biodiesel e apresentava a seguinte composição: Glicerol 80,5\%; Umidade 12,8\%; $\mathrm{NaCl} 6,3 \%$ e Ácidos Graxos 0,4\%. As vís-

\footnotetext{
${ }^{1}$ Recebido em 27 de setembro de 2012.

Aceito para publicação em 3 de janeiro de 2013.

${ }^{2}$ Centro de Ciências Biológicas e da Natureza, Universidade Federal do Acre, Rodov. BR 364 Km 4, Rio Branco, AC 69915-900, Brasil. *Autor para correspondência: ykaracas@yahoo.com.br

${ }^{3}$ Departamento de Zootecnia, Escola Superior de Agricultura "Luiz de Queiroz", Universidade de São Paulo, Av. Pádua Dias 11, Piracicaba, SP 13418-900, Brasil.

${ }^{4}$ Departamento de Cirurgia, Faculdade de Medicina Veterinária e Zootecnia (FMVZ), Universidade de São Paulo (USP), Av. Prof. Dr. Orlando Marques de Paiva 87, São Paulo, SP 05508-270, Brasil.
}

ceras foram resfriadas, dissecadas, fixadas, desidratadas e glicerinizadas. Os órgãos foram mensurados, analisados e fotodocumentados antes e após protocolo de preservação. A glicerina semipurificada promoveu discreta diminuição nas dimensões das estruturas anatômicas (massa, altura e largura), todavia não houve diferença estatística. Essa glicerina preservou as características de consistência flexibilidade das peças anatômicas, além de reduzir o custo e a eliminação dos gases tóxicos. 0 principal alcance deste estudo foi a preservação das características morfológicas e a melhoria do processo ensino-aprendizagem.

TERMOS DE INDEXAÇÃO: Glicerina semipurificada, conservação, biodiesel, peças anatômicas.

\section{INTRODUÇÃO}

As técnicas de conservação na anatomia têm o propósito de preservar as características morfológicas das peças anatômicas quanto à coloração, consistência e flexibilidade de tecido. Adicionalmente também protege contra a deterioração, mantendo os tecidos firmes e insolúveis (Rodrigues 2010). Dentre os fixadores mais utilizados na anatomia 
temos o formaldeído e a glicerina (Fox et al. 1985, Greer 1991, Rodrigues 2010).

0 formaldeído é o fixador e conservante amplamente utilizado em laboratório de anatomia, devido ao baixo custo e a alta eficiência (Mies 1994). Por outro lado, a toxicidade do formaldeído causa irritação nos olhos e mucosas, podendo prejudicar o ensino em anatomia (Karlsen et al. 1994, Hammer et al. 2011). Ademais a exposição contínua a esse produto foi relatada como um possível desencadeador de tumores (Hauptmann et al. 2009, Viegas et al. 2010).

A glicerina pura por sua vez garante a preservação, permite a transparência e manuseio do tecido facilitando o estudo anatômico, além de eliminar poucos vapores no ambiente (Alvarenga 1992, Silva et al. 2008, An et al. 2011). Entretanto, o seu custo é considerado alto e inviável para muitos laboratórios de anatomia.

Uma alternativa ao uso da glicerina pura é o uso da glicerina semipurificada proveniente da produção do biodiesel, a qual corresponde a 10\% do volume total (Dasari et al. 2005, Rivaldi et al. 2007, Oliveira 2008). Essa glicerina não tem destino certo, sendo poluente quando descartada no ambiente sem nenhum critério, o que acarreta em aumento no custo da produção e armazenamento (Rivaldi et al. 2007).

0 propósito do estudo foi demonstrar a viabilidade da glicerina semipurificada na conservação de peças anatômicas a baixo custo, além de buscar uma finalidade sustentável para esse coproduto do biodiesel.

\section{MATERIAL E MÉTODOS}

Foram coletados 15 corações e 30 rins de suínos oriundos da doação de frigorífico comercial. Os animais foram selecionados randomicamente e abatidos para consumo de acordo com os regulamentos do Ministério da Agricultura Pecuária e Abastecimento do Brasil, sob Inspeção Estadual. Os órgãos foram transportados e armazenados em isopor contendo gelo reciclável a temperatura aproximada de $4{ }^{\circ} \mathrm{C}$ durante 12 horas. Posteriormente o procedimento de conservação dos órgãos foi realizado no Laboratório de Anatomia Animal da Universidade Federal do Acre. A glicerina foi adquirida em uma usina de biodiesel da região Centro-Oeste do Brasil, a qual apresentava a seguinte composição: Glicerol 80,5\%; Umidade 12,8\%; $\mathrm{NaCl}$ 6,3\% e Ácidos Graxos 0,4\%, sendo caracterizada como semipurificada (Fig.1).

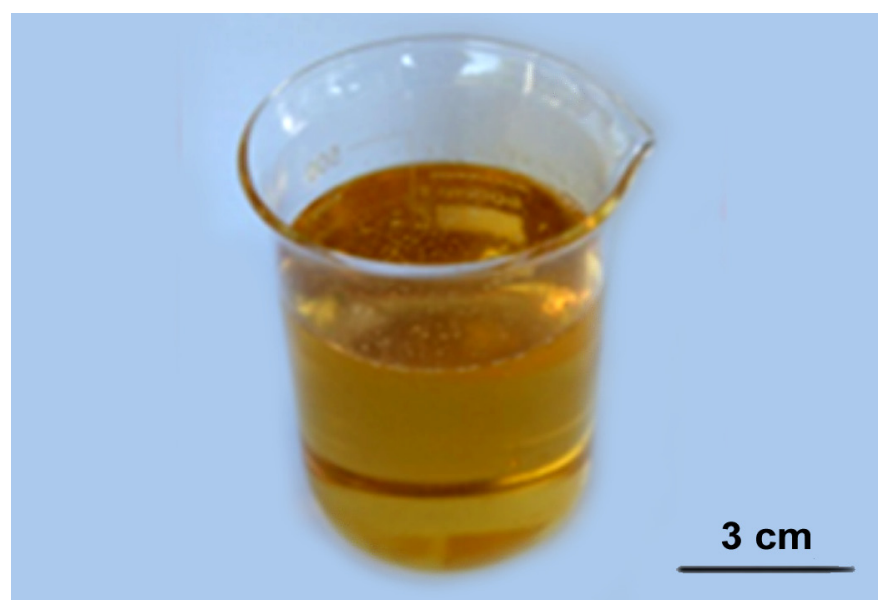

Fig.1. Amostra de glicerina semipurificada.
No laboratório os órgãos foram submetidos aos seguintes procedimentos: (a) Dissecação; (b) Fixação em solução de formaldeído a $10 \%$ por dois dias; (c) Desidratação em solução de álcool etílico a 70\% por sete dias; (d) Glicerinação em solução de glicerina e álcool etílico 100\%, na proporção de 1:2 (glicerina:álcool), por 15 dias.

Após o processo de glicerinação as peças foram acondicionadas em caixas plásticas, à temperatura ambiente, e observadas diariamente por um período de 180 dias a fim de verificar a necessidade de serem submetidas ao processo novamente. Adicionalmente as peças foram monitoradas para observação macroscópica de colônias sugestivas de crescimento de microbiano.

Ao término de cada procedimento foi executado o registro fotográfico e a mensuração da massa, altura e largura dos corações e rins com o auxílio de paquímetro e balança digital.

Os resultados foram analisados estatisticamente pela análise de variância (ANOVA), e quando necessário as médias foram comparadas utilizando o método de Tukey ao nível de 5,0\% de probabilidade.

\section{RESULTADOS}

Os órgãos após o processo de glicerinação apresentaram coloração amarelada proveniente da amostra de glicerina (Fig.2 e 3). A glicerina conservou de maneira adequada os órgãos externa e internamente, preservando as características de consistência e flexibilidade das peças anatômicas (Fig.4).

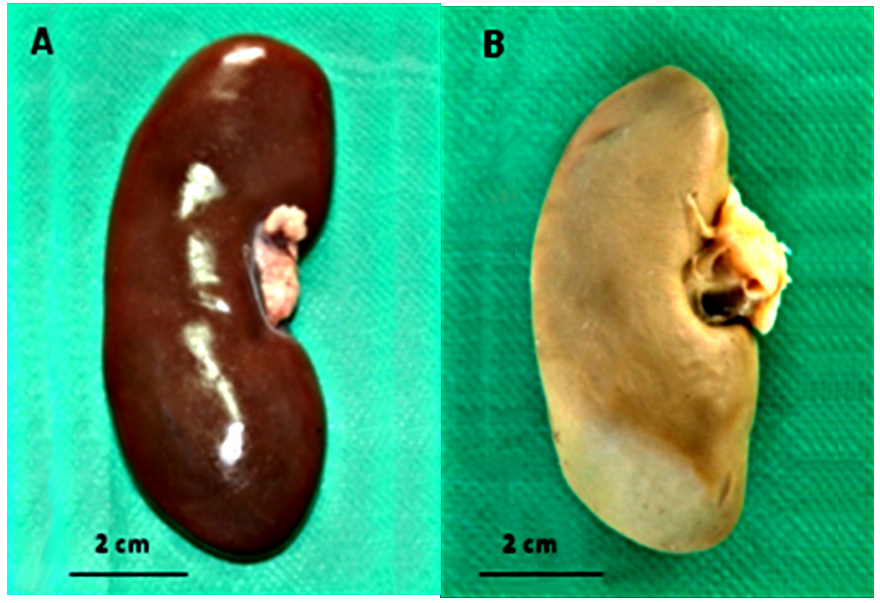

Fig.2. Rim de suíno. (A) Dissecação. (B) Glicerinação.

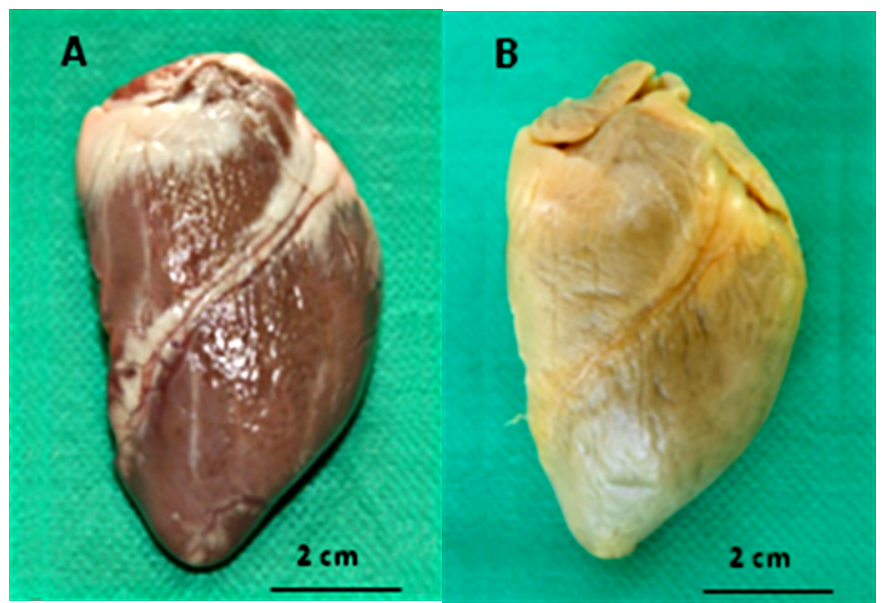

Fig.3. Coração de suíno. (A) Dissecação. B) Glicerinação. 


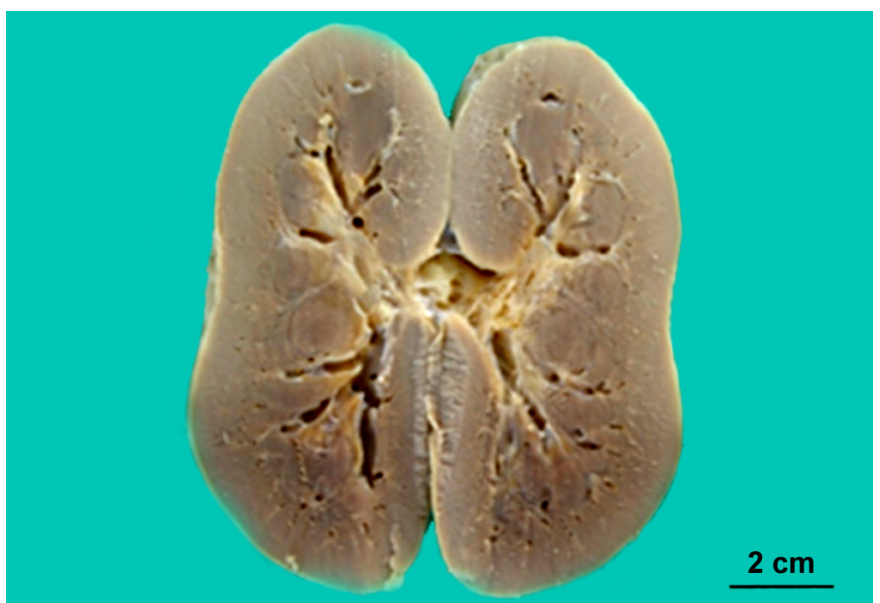

Fig.4. Rim de suíno. Vista interna.

A utilização da glicerina promoveu discreta diminuição dos órgãos e consequentemente nas dimensões das estruturas anatômicas (massa, altura e largura), todavia não houve diferença estatística (Quadro 1).

Na manipulação foi observada facilidade do manuseio, leveza, flexibilidade e visualização das estruturas anatômicas. Ademais foi presenciada a diminuição dos odores, quando comparada com as peças anteriormente conservadas em formaldeído.

Após o processo de glicerinação das peças não houve a necessidade de imersão do material em solução de conservação, permitindo o armazenamento vertical das mesmas, sem a necessidade de submeter os órgãos novamente ao processo de glicerinação. Não foi possível observar macroscopicamente a presença de colônias sugestivas de contaminação microbiana na superfície dos órgãos.

\begin{tabular}{|c|c|c|c|c|c|}
\hline & \multicolumn{2}{|l|}{ Coração } & \multicolumn{3}{|c|}{ Rim } \\
\hline $\begin{array}{c}\text { Massa } \\
(\mathrm{g})\end{array}$ & $\begin{array}{c}\text { Altura } \\
(\mathrm{mm})\end{array}$ & $\begin{array}{c}\text { Largura } \\
(\mathrm{mm})\end{array}$ & $\begin{array}{c}\text { Massa } \\
(\mathrm{g})\end{array}$ & $\begin{array}{c}\text { Altura } \\
\text { (mm) }\end{array}$ & $\begin{array}{c}\text { Largura } \\
(\mathrm{mm})\end{array}$ \\
\hline
\end{tabular}

Dissecação $113,7 \pm 43,6 \quad 74,3 \pm 4,6 \quad 61,9 \pm 11,5 \quad 59,2 \pm 12,995,8 \pm 12,6 \quad 50,2 \pm 5,6$ Glicerinação $107,0 \pm 38,2 \quad 73,5 \pm 2,8 \quad 60,6 \pm 11,2 \quad 58,7 \pm 13,6 \quad 88,5 \pm 9,2 \quad 88,5 \pm 9,2$

\section{DISCUSSÃO}

Segundo Silva et al. (2008) a glicerina deve ter acima de 95\% de glicerol em sua composição para conservação adequada das peças anatômicas. Entretanto, os $80 \%$ de glicerol encontrado na glicerina proveniente da produção de biodiesel foram suficientes para o processo, pois conservou de maneira adequada os órgãos externa e internamente, preservando as características de consistência e flexibilidade das peças anatômicas.

A glicerina isolada ou associada ao cloreto de sódio tem ação anti-séptica, atuando contra fungos e bactérias (Pigossi 1964, Alvarenga 1992, Silva et al. 2008). Neste contexto, observou-se que a glicerina proveniente do biodiesel apresenta em torno de $6 \%$ de cloreto de sódio em sua composição, o que potencialmente evitou a proliferação de microrganismos, sobretudo de fungos.
Gigek et al. (2009) descreveram que o processo de glicerinação permite maior clareza das peças, resultando em melhor identificação das estruturas anatômicas quando comparadas a conservação em formaldeído, o que facilita o estudo prático de anatomia. Já Costenaro (2009) relatou que a glicerina proveniente do biodiesel apresenta coloração amarelada. Em nossos achados as peças apresentaram aspecto amarelado proveniente da amostra de glicerina semipurificada utilizada, entretanto esse fato não impediu a identificação das estruturas anatômicas.

Segundo Silva et al. (2008) as dimensões dos órgãos submetidos ao processo de glicerinação sofrem discreta diminuição, o que correspondeu ao nossos achados. A discreta diminuição não interferiu na visualização das estruturas anatômicas e manteve a massa das peças muito próximo ao encontrado antes da utilização da técnica, devido ao não encharcamento das peças, fato este semelhante ao descrito por Gigek et al. (2009).

Segundo Monteiro (1960) e Silva et al. (2008) a glicerina reduz a massa dos órgãos facilitando o seu manuseio, o que pode ser considerado uma vantagem.

De acordo com Roe et al. (1988) e Hammer et al. (2011) a glicerina mantém as peças anatômicas inodoras e preserva suas características de consistência e flexibilidade, o que correspondeu aos nossos achados.

A glicerina conservou as peças anatômicas de maneira adequada, com uma boa penetração nos órgãos, fato este também observado por Silva et al. (2008) quando utilizou a glicerina pura. As peças submetidas ao processo de glicerinação não necessitaram de conservação em cubas, o que otimizou o espaço do laboratório, armazenando as mesmas de maneira verticalizada.

Segundo Nascimento et al. (2009) a glicerina semipurificada formada no processo de formação do biodiesel apresenta constituição variável de acordo com a matéria prima e processo utilizado. No presente estudo a composição da glicerina foi satisfatória para a conservação das peças anatômicas. Entretanto, a composição da glicerina a ser utilizada deve ser previamente conhecida para uma perfeita conservação.

A glicerina proveniente do biodiesel é um meio viável e menos tóxico na conservação de peças anatômicas. Essa adaptação permitiu redução no custo, diminuição da liberação de gases tóxicos, armazenamento verticalizado sem o mergulho das peças em cubas, além de preservar as características morfológicas das peças anatômicas não interferindo na relação ensino-aprendizagem.

\section{REFERÊNCIAS}

Alvarenga J. 1992. Possibilidades e limitações da utilização de membranas biológicas preservadas em cirurgia, p.33-39. In: Daleck C.R. (Ed.), Tópicos em Cirurgia de Cães e Gatos. Fundação de Estudos e Pesquisas em Agronomia, Jaboticabal, SP.

An X., Yue B., Lee J.H., Lin C. \& Han S.H. 2011. Arterial anatomy of the gracilis muscle as determined by latex injection and glycerin transparency. Clin. Anat., Rochester, doi:10.1002/ca.21217.

Costenaro H.S. 2009. Hidrólise ácida e retirada de sais da glicerina bruta proveniente da produção do biodiesel. Dissertação de Mestrado em Engenharia Química, Escola Politécnica, Universidade de São Paulo, São Paulo, SP. 136p. 
Fox C.H., Johnson F.B., Whithing J. \& Roller P.P. 1985. Formaldehyde fixation. J. Histochem. Cytochem. 33:843-853.

Gigek T., Oliveira J.E.M., Neto A.C.A., Carvalho W.L. Pereira F.V. \& Almeida A.H. 2009. Estudo Analítico da Técnica de Glicerinação Empregada para Conservação de Peças Anatômicas de Bovinos. Anais V Simpósio de Ciências da Unesp, Dracena, SP, p.1-3. (Resumo)

Greer C.E., Peterson S.L., Kiviat N.B. \& Manos M.M. 1991. PCR amplification from paraffin-embedded tissues: Effects of fixative and fixation time. Am. J. Clin. Pathol. 95:117-124.

Hammer N., Löffler S., Feja C., Bechmann I. \& Steinke H. 2011. Substitution of formaldehyde in cross anatomy is possible. J. Natl Cancer Inst. 103:610-611.

Hauptmann M., Stewart P.A., Lubin J.H., Freeman L.E.B., Hornung R.W., Herrick R.F., Hoover R.N., Fraumeni J.F., Blair A. \& Hayes R.B. 2009. Mortality from lymphohematopoietic malignancies and brain cancer among embalmers exposed to formaldehyde. J. Natl Cancer Inst. 101:1696-1708.

Karlsen E., Kalantari M., Chitemerere M., Johannson B. \& Hagmar B. 1994. Modifications of human and viral deoxyribonucleic acid by formaldehyde fixation. Lab. Invest. 71:604-611.

Mies C. 1994. Molecular biological analysis of paraffin-embedded tissues. Hum. Pathol. 25:555-560.

Monteiro A.U. 1960. Montagem de parasitas, artrópodes e peças anatômicas em Meio Sólido. Revta Inst. Med. Trop., São Paulo, 2:121-124.

Nascimento U.M., Vasconcelos A.C.S., Azevedo E.B. \& Silva F.C. 2009. Oti- mização da produção de biodiesel a partir de óleo de coco babaçu com aquecimento por microondas. Eclet. Quím. 34:37-48.

Oliveira M. 2008. Glicerina que sobra da produção de biodiesel será usada para produzir polipropileno. FAPESP. Disponível em <http://revistapesquisa.fapesp.br/?art=3581\&bd=1\&pg=1\&lg=> Acesso em 10 out. 2011.

Pigossi N. 1964. Implantação de dura-mater homógena conservada em glicerina: estudo experimental em cães. Tese de Doutorado em Medicina, Faculdade de Medicina, Universidade de São Paulo, São Paulo, SP. 41p.

Rivaldi J.D., Sarrouh B.F. \& Fiorillo R. 2007. Glicerol de biodiesel. Biotecnol. Ciênc. Desenvolv. 37:44-51.

Rodrigues H. 2010. Técnicas Anatômicas. $4^{\text {th }}$ ed. GM Gráfica e Editora, Vitória, ES. 269p.

Roe S.C., Pijanowsky G.J. \& Johnson A.L. 1988. Biomechanical properties of canine cortical bone allografts: Effects of preparation and storage. Am. J. Vet. Res. 49:873-877.

Silva E.M., Dias G., Tavares M., Marques T. \& Furtado J.M. 2008. Estudo analítico da técnica de glicerinação empregada para conservação de peças anatômicas: experiência da disciplina de Anatomia Humana do Departamento de Morfologia da UniFOA. Cadernos UniFOA, Volta Redonda, RJ, p.66-69. (Resumo)

Viegas S., Nunes C., Malta-Vacas J., Gomes M., Brito M., Mendonça P. \& Prista J. 2010. Genotoxic effects in occupational exposure to formaldehyde: a study in anatomy and pathology laboratories and formaldehyde -resins production. J. Occup. Med. Toxicol. 5:1-8. 